\title{
Cigarette Smoke Causes Changes in Liver and Spleen of Mice Newborn Exposed During Pregnancy
}

\author{
Diniz MF ${ }^{1}$, Dourado VA ${ }^{1}$, Silva $\mathrm{ME}^{2}$, Pedrosa $\mathrm{ML}^{3}$, Bezerra FS $^{3}$ and Lima WG $^{3 *}$
}

${ }^{1}$ Department of Medicine, Federal University of Ouro Preto (UFOP), Brazil

${ }^{2}$ Department of Food (DEALI), Federal University of Ouro Preto (UFOP), Brazil

${ }^{3}$ Department of Biological Sciences (DECBI), Federal University of Ouro Preto (UFOP), Brazil

\begin{abstract}
Cigarette smoking can lead to pivotal morphological changes in several human and animal tissues, especially when the exposure occurs during neonatal life. We evaluated the livers and spleens of C57BL/6 neonatal mice to determine possible morphological changes induced by exposure to cigarette smoke. In total, 15 C57BL/6 adult mice were used for mating, placing 2 female mice per male mouse for a 5-day period. Pregnant female mice were divided into 2 groups: the first group (ICS21) consisted of 5 female mice that were exposed to 4 cigarettes, 3 times daily for 21 days. They were subjected to $6 \mathrm{~min}$ of exposure per cigarette in an inhalation chamber. The second group (CG) consisted of 5 female mice that were not exposed to cigarette smoking and was used as a control group. Seven neonatal mice from both groups were weighed $24 \mathrm{~h}$ post-birth and then euthanized. Their livers and spleens were weighed and fixed for routine histological processing. Morphometric analysis was used to assess possible hepatic inflammation, measure hepatic glycogen and collagen deposition areas. Total spleen area, white pulp, and red pulp were identified. A reduction in body weight was observed in ICS21 mice as compared to CG mice, and a similar trend was observed in the liver and spleen weights. Histological analysis indicated the presence of more number of inflammatory cells in the ICS21 livers than that in the CG livers. Moreover, smaller hepatic glycogen deposition areas were observed in ICS21 mice than that in CG mice. However, no difference in hepatic collagen deposition was observed between the 2 groups. No differences were observed in the areas of the total organ and the white and red pulp areas between the 2 groups. However, the proportion of the white pulp and total area was lower in the ICS21 spleens than that in the CG spleens. Our results indicate that exposure to cigarette smoke during neonatal life can induce changes in fetal tissues, which translate to several changes in the organs of the neonatal mice.
\end{abstract}

Keywords: Cigarette smoke; Liver; Spleen; Newborn

\section{Introduction}

Tobacco use by pregnant women leads to changes in fetal organ development, which often leads to negative consequences in the offspring's life, such as depression and formation of depressionassociated immune diseases [1-3]. Approximately 20\%-50\% of women report smoking during early pregnancy [4], and 50\% of pregnant nonsmokers are exposed to secondhand smoking during pregnancy [5]. Maternal smoking is associated with fetal growth retardation, increased risk of premature delivery, low birth weight $[6,7]$, and an increased risk of obesity in the offspring [8,9]. Obstetric and fetal complications associated with smoking include placental abruption [10], spontaneous abortion [11], and sudden infant death syndrome [12,13].

The pathophysiology of tissue damage associated with cigarette smoke and the oxidant/antioxidant imbalance caused by the release of reactive oxygen species have been widely studied. Oxidative stress occurs when free radicals formation exceed the defense promoted by antioxidants agents. Tobacco use causes the release of many substances in the body that have the direct potential of forming free radicals and activating inflammatory cells, such as macrophages and neutrophils, which also produce reactive oxygen species, ultimately increasing the tissue concentration of harmful substances. An important method for assessing oxidative damage of lipids, which is common in active and passive smoking, is the Thiobarbituric Acid Reactive Substances (TBARS) assay that measures malondialdehyde levels [14]. In response to oxidative stress, antioxidants are activated to neutralize the oxidants and prevent tissue damage [15]. The antioxidant defense system includes antioxidant enzymes such as Superoxide Dismutase (SOD), Catalase (CAT), and Glutathione Peroxidase (GPx) [16].

Because of their roles in the postpartum period and during development, the liver and spleen are essential for metabolizing toxic substances and regulating the immune system's reaction to these substances. This study aimed at quantitatively and qualitatively evaluating the inflammatory changes that occur in the liver and spleen of neonatal animals that were exposed to cigarette smoke during pregnancy.

\section{Materials and Methods}

\section{Animals}

Animal care and experimental procedures were approved by the Ethics Committee on Animal Use (CEUA) at the Federal University of Ouro Preto (UFOP), under protocol number 2010/047, and they followed the rules established by the Brazilian Society of Laboratory Animal Science (SBCAL). During all experiments, animals were kept at ambient temperature $\left(21^{\circ} \mathrm{C} \pm 2^{\circ} \mathrm{C}\right)$ and light cycles controlled vivarium at the School of Nutrition (UFOP), with food and drinking water ad

*Corresponding author: Wanderson Geraldo de Lima, Associate Professor, Department of Biological Sciences (DECBI), Federal University of Ouro Preto (UFOP), Institute of Biological Sciences and Department of Biological Sciences, Campus Morro do Cruzeiro, Ouro Preto, Minas Gerais, Brazil-35400-000, Tel: +5531 3559-1261; E-mail: wanderson@ufop.br

Received January 22, 2012; Accepted March 15, 2013; Published March 18, 2013

Citation: Diniz MF, Dourado VA, Silva ME, Pedrosa ML, Bezerra FS, et al. (2013) Cigarette Smoke Causes Changes in Liver and Spleen of Mice Newborn Exposed During Pregnancy. J Cytol Histol 4: 168. doi:10.4172/2157-7099.1000168

Copyright: $\odot 2013$ Diniz MF, et al. This is an open-access article distributed under the terms of the Creative Commons Attribution License, which permits unrestricted use, distribution, and reproduction in any medium, provided the original author and source are credited. 
libitum. For breeding, 10 female and 5 male mice, (approximately $25 \mathrm{~g}$ and $31 \mathrm{~g}$ each, respectively) all of the Mus musculus strain C57BL/6, were used. Mating occurred through placing 2 female mice and 1 male mouse in a breeding box for a 5-day period. Pregnancy in the female mice was confirmed through observation of the vaginal plug and the vaginal smear [17]. Pregnant female mice were randomly divided into 2 groups: ICS21 (group inhaling cigarette smoke), consisting of 5 pregnant female mice that were subjected to inhalation of cigarette smoke for 21 days during pregnancy, and CG (control group), consisting of 5 pregnant female mice that were exposed to ambient air.

\section{Exposure to cigarette smoke}

Pregnant animals' exposure to cigarette smoke occurred during the 21 days of gestation and was performed according to procedures described by Valenca et al. [18]. In an inhalation chamber, ICS21 mice were exposed to smoke from 12 commercial cigarettes per day, divided into 3 daily exposures. At the time of each exposure, a single cigarette (10 mg tar, $0.8 \mathrm{mg}$ nicotine, and $10 \mathrm{mg}$ of carbon monoxide) was attached to a $60 \mathrm{~mL}$ glass syringe to collect smoke for insufflations. Smoke was collected and immediately introduced into the inhalation chamber, where it was left for $6 \mathrm{~min}$, then the chamber was opened for 1 min with total exhaustion of cigarette smoke, and this procedure was repeated for each cigarette [19].

\section{Euthanasia and tissue collection}

Euthanasia of neonatal mice was performed through decapitation $24 \mathrm{~h}$ after the birth of the animals from both groups. In total, 14 neonatal animals from the ICS21 and CG groups were euthanized. After decapitation, animals were perfused with $0.9 \%$ saline solution, and the liver and spleen were collected and weighed. The organs were each sectioned into 2 samples. The first sample was fixed in buffered formalin solution for at least $48 \mathrm{~h}$ to be used in the histological analysis, and the second sample was immediately frozen at $-70^{\circ} \mathrm{C}$ to be used in the biochemical analysis.

\section{Histological staining and morphometric analysis}

After fixation, the liver and spleen tissue samples were processed according to routine histological techniques and embedded in paraffin blocks. Paraffin blocks were sectioned using a microtome into $4 \mu \mathrm{m}$ thick sections, placed onto glass slides, and fixed for histological staining. Staining was performed using hematoxylin-eosin and Picrosirius-red (Bio-Optica, Milano, Italy) and periodic acid-Schiff (Bio-Optica, Milano, Italy).

All morphometric analysis was performed at the Multiuser Laboratory of the Research Center for Biological Sciences, Federal University of Ouro Preto. For counting the number of inflammatory cells present in the hepatic lobes, measured the different spleen areas, quantified the collagen fibers, quantified the glycogen deposition and determined the splenic capsule thickness we obtained 20 images randomly from histological slides that were prepared from the liver and spleen sections. These slides were scanned using the Leica Applicatoin software, and analyzed using the Leica Q-Win Plus software (Leica Microsystems, Inc., Buffalo Grove, Illinois, USA) [20].

\section{Statistical analysis}

All data was presented as mean \pm standard error of the mean. Statistical analysis was performed using the Student's $t$-test, unpaired for comparison between the 2 groups. The software used was GraphPad Prism 5.0 (GraphPad Software, Inc., La Jolla, California, USA). Differences were considered significant at $\mathrm{p}<0.05$.

\section{Results}

\section{Biometric analysis}

Body mass and body length measurements were lower in neonatal animal exposed to cigarette smoke during fetal life than that in the control animals. Similarly, the liver and spleen weights of the ICS21 animals were lower than that of the CG animals (Table 1).

\section{Morphometric liver analysis}

A difference between the number of inflammatory cells in the livers of the CG (170.30 \pm 17.62 total cells per microscopic field $)$ and

\begin{tabular}{|l|c|c|c|}
\hline & CG & ICS21 & $p$ \\
\hline Animal weight $(\mathrm{g})$ & $1.29 \pm 0.02$ & $1.18 \pm 0.01$ & $0.005^{\mathrm{a}}$ \\
\hline Liver weight $\times 10^{-2}(\mathrm{~g})$ & $6.24 \pm 0.35$ & $5.02 \pm 0.28$ & $0.028^{\mathrm{a}}$ \\
\hline Spleen weight $\times 10^{-3}(\mathrm{~g})$ & $5.28 \pm 0.42$ & $3.40 \pm 0.51$ & $0.016^{\mathrm{a}}$ \\
\hline Body length $(\mathrm{cm})$ & $3.21 \pm 0.04$ & $2.90 \pm 0.06$ & $0.009^{\mathrm{b}}$ \\
\hline
\end{tabular}

Table 1: Biometric dates of CG and ICS21 animals. Results are presented as mean \pm SEM. CG: control group; ICS21: Inhalation Cigarette Smoke during Pregnancy

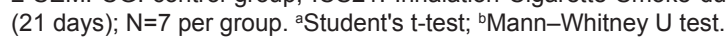
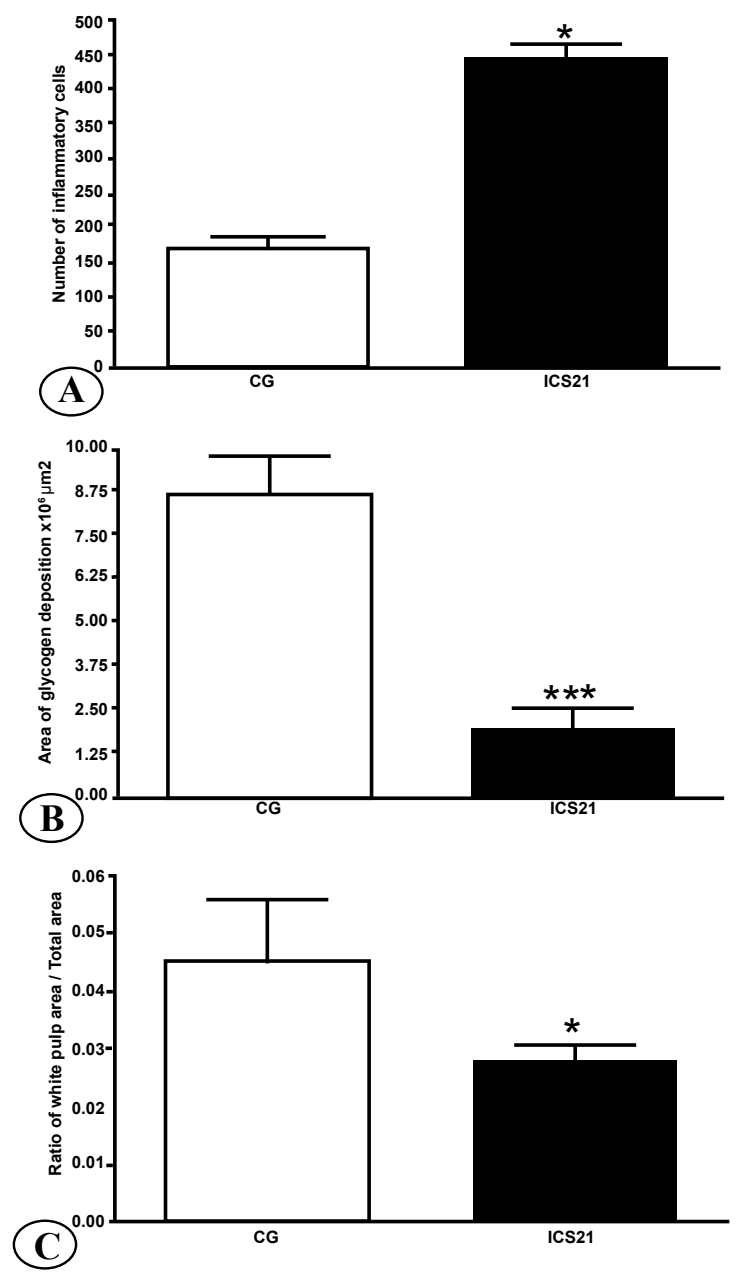

Figure 1: Morphometric liver and spleen analysis. A) Number of inflammatory cells in hepatic tissue, $p<0.0001$. B) Quantification of hepatic glycogen in the animals studied, $p=0.0004$. C) Relationship between area of white pulp and the total area, $p=0.0469$. CG: Control Group; ICS21: Inhalation Cigarette Smoke During Pregnancy (21 days); N=7 per group. 
Citation: Diniz MF, Dourado VA, Silva ME, Pedrosa ML, Bezerra FS, et al. (2013) Cigarette Smoke Causes Changes in Liver and Spleen of Mice Newborn Exposed During Pregnancy. J Cytol Histol 4: 168. doi:10.4172/2157-7099.1000168

Page 3 of 5

ICS21 (444.70 \pm 24.21 total cells per microscopic field) animals was detected $(\mathrm{p}<0.0001)$, such that an extensive migration of inflammatory cells was observed in ICS21 animals (Figure 1A). In these animals, eosinophils, neutrophils, and other leukocytes were detected in large numbers in the liver parenchyma, compared with the control group that exhibited highly conserved hepatocyte morphology (Figure 2). The glycogen deposition area in the CG animals $\left(8.6 \pm 1.13 \times 10^{6} \mu \mathrm{m}^{2}\right)$ was larger than that observed in ICS21 animals $\left(1.92 \pm 0.59 \times 10^{6} \mu \mathrm{m}^{2}\right)$, $\mathrm{p}=0.0004$ (Figure 1B and Figure 3). Hepatic fibrosis was not observed in the animals studied, however, ICS21 animal presents morphological characteristics of steatosis evaluable by histological slides.

\section{Morphometric spleen analysis}

The splenic morphological structures of ICS21 animals appeared less organized than that of CG animals, making it difficult to identify the white pulps regions. The quantitative morphometric evaluations revealed no differences in the total splenic area between CG and ICS21 animals. Furthermore, no differences were found in the splenic capsule thickness and in the white and red pulp areas between both groups (Table 2). However, the proportion of white pulp area and total area was higher in the spleens of the CG animals than that in the spleens of the animals ICS21 $\left(4.53 \pm 1.07 \times 10^{-2} \times 2.79 \pm 0.25 \times 10^{-2}\right.$, respectively), $\mathrm{p}=0.0469$ (Figure $1 \mathrm{C}$ and Figure 4 ).

\section{Discussion}

In this study, we investigated morphological changes in the livers and spleens of animals exposed to cigarette smoke during their fetal life. Our findings support the hypothesis that cigarette smoking during

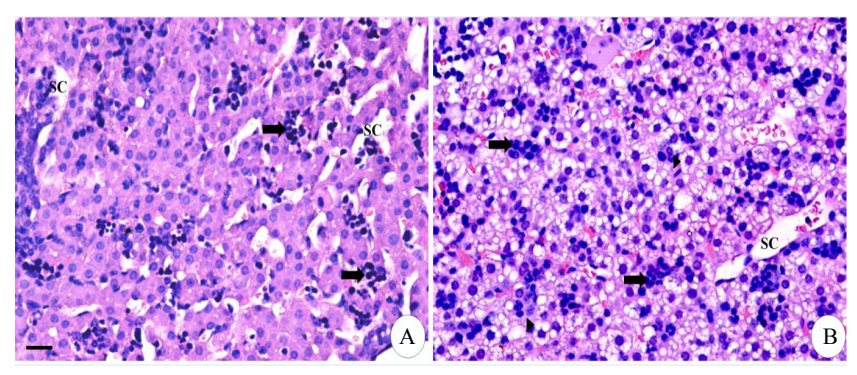

Figure 2: Photomicrographs of liver from C57BL/6 neonates euthanized after 24 hours of life, the color used was Hematoxylin-eosin. A) CG with liver parenchymal preserved. B) Liver ICS21 with increase in inflammatory cells (arrows) and large hepatocytes with the presence of morphological aspect of steatosis (arrow head). SC: Sinusoid Capillary; Bar: $20 \mu \mathrm{m}$.

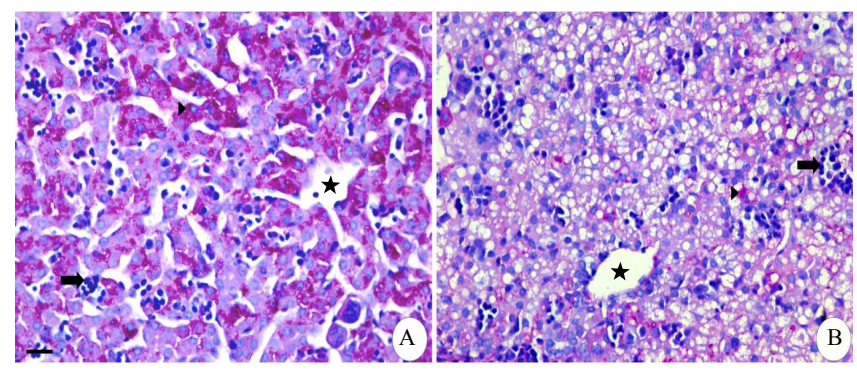

Figure 3: Photomicrographs of liver from C57BL/6 neonates in the group exposed to cigarette smoke during pregnancy ( 21 days). The color used was periodic acid-Schiff (PAS) which stains glycogen in purple fabric, this way it is possible to identify the deposition of liver glycogen. A) Liver CG with vast storehouse of glycogen. B) Liver ICS21 with decreased glycogen in hepatocytes (head arrows). Arrow: inflammatory cells; Star: central vein; Bar: $20 \mu \mathrm{m}$.

\begin{tabular}{|l|c|c|c|}
\hline & CG & ICS21 & $p$ \\
\hline Total area spleen $\left(10^{5} \mu \mathrm{m}\right)$ & $9.88 \pm 2.09$ & $9.61 \pm 1.39$ & $0.92^{\mathrm{a}}$ \\
\hline Area of white pulp of the spleen $\left(10^{4} \mu \mathrm{m}\right)$ & $4.65 \pm 1.33$ & $3.16 \pm 0.52$ & $0.41^{\mathrm{b}}$ \\
\hline Area of red pulp of the spleen $\left(10^{6} \mu \mathrm{m}\right)$ & $0.99 \pm 0.24$ & $1.08 \pm 0.13$ & $0.82^{\mathrm{b}}$ \\
\hline Thickness trabecula $\left(10^{1} \mu \mathrm{m}\right)$ & $3.86 \pm 0.40$ & $3.28 \pm 0.22$ & $0.37^{\mathrm{b}}$ \\
\hline
\end{tabular}

Table 2: Measurements of the total areas, white pulp, red pulp and splenic trabecular thickness. Results are presented as mean \pm SEM. CG: control group ICS21: inhalation cigarette smoke during pregnancy (21 days); $\mathrm{N}=7$ per group. Student's t-test; ${ }^{\mathrm{b}}$ Mann-Whitney U test.
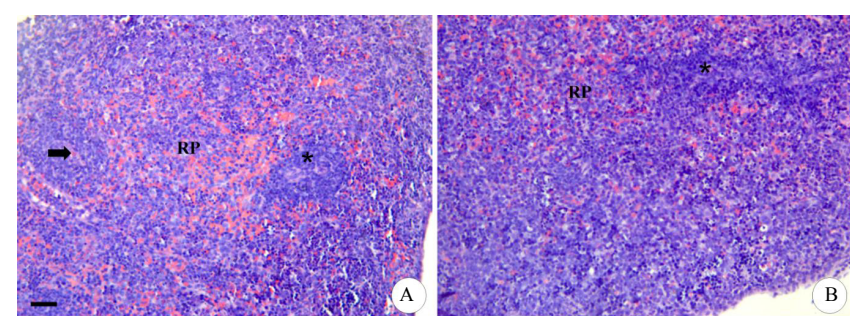

Figure 4: Photomicrographs of spleen of neonatal mice euthanized after 24 hours of life. A) CG with visible delineation of spleen pulps. It is noticed formation of white saves around the central arteriole (arrow). B) ICS21 showing undefined boundary between white pulp (asterisk) and red pulp (RP). H and E. Bar: $20 \mu \mathrm{m}$.

pregnancy alters body mass, as well as liver and spleen mass, and reduces the body length of neonates. A groundbreaking study conducted by Simpson [21] linked the low birth weight of pups to maternal exposure to cigarette smoke. Moreover, a study conducted by Chen et al. [22] reported a decrease in the liver mass of offspring who were exposed to cigarette smoke during pregnancy. The decrease in the size of the puppies can be associated to maternal stress during the gestational period. Pollard [23] studying maternal stress induced by high-anxiety observed similarly decrease of body length as observed in our model of cigarette smoke exposition.

The relatively low weights of organs and animals could be caused by several factors. Vascular changes due to nicotine and carbon monoxide could limit the mother's delivery of nutrients to the fetus, restricting intrauterine growth. Similarly, catecholamine release from the adrenal glands and nerve cells due to the exposure to cigarette smoke can cause vasoconstriction, limiting placental blood flow and restricting intrauterine nutrition [24] and fetal oxygenation [25]. Low birth weight is a risk factor for many diseases, including diabetes, hypertension, cardiovascular disease, and renal disease [26]. In response to malnutrition, nutrients are selectively distributed to preserve brain growth, reducing the supply to other less vital organs. These adaptations could limit the cell number in organs such as the liver and muscles by altering the metabolism of glucose and fat [27].

The cigarette smoke effects under body mass and organ development is directly influenced by initial time of exposition. We promote the cigarette smoke exposition since of first day of pregnancy confirmation. Esposito et al. [28] reported that while exposure of pregnant female C57BL/6 mice to cigarette smoke during the first 5 days of pregnancy caused low birth weight in the offspring, exposure after the initial 5-day period of pregnancy caused no changes in the offspring body weight.

Our splenic morphological evaluations showed lower proportion of white pulp area and total area in spleen of cigarette smoke puppies suggesting immune response alterations in these animals. A study conducted by Herscowitz et al. [29] reported that there is no difference in the magnitude of splenic cell formation in response to gestational 
Citation: Diniz MF, Dourado VA, Silva ME, Pedrosa ML, Bezerra FS, et al. (2013) Cigarette Smoke Causes Changes in Liver and Spleen of Mice Newborn Exposed During Pregnancy. J Cytol Histol 4: 168. doi:10.4172/2157-7099.1000168

exposure to cigarette smoke. However, the study reported an inhibition of maturation and splenic antibody response, indicating that exposure to cigarette smoke has immunosuppressive effects. Similarly, Singh et al. [3] reported changes in the cell profile of lymphoid organs, such as the spleen, in mice exposed to cigarette smoke during the neonatal period, which results in deficient immune responses and indicates immunosuppression in these neonates.

Maternal smoking can lead to many related disorders, such as insulin resistance, obesity and glucose intolerance, in both the childhood and adulthood of the offspring [30,31]. Insulin signaling in the brain is required to inhibit glucose synthesis in the liver [32], and glucose metabolism in the brain can also regulate blood lipid levels [33]. Previously studies suggests that the dysfunction of insulin function in the brain would cause a decrease in liver glycogen levels, since glucose cannot be absorbed and stored as glycogen, as has been observed in neonates of females exposed to cigarette smoke during pregnancy [22].

Histopathological observations of neonates exposed to cigarette smoke during fetal life in our study showed histological picture characterized by parenchyma inflammation and cellular degeneration in the liver parenchyma, but showed no fibrotic tissue repair. According to D'Agostini et al. [34], in similarly model exposure to cigarette smoke after birth causes pathological changes that include parenchymal liver dystrophy, which were not observed in the control animals.

\section{Conclusion}

To our knowledge, this is the first study demonstrating the effects of cigarette smoke on the livers and spleens of C57BL/6 mice exposed to smoke during their fetal life. The study examined changes in biometric parameters, the influx of inflammatory cells into the liver parenchyma, the formation of splenic white pulp, and glycogen deposition, between control animals and animals exposed to cigarette smoke. Future studies will be necessary to determine the mechanisms responsible to histological found, opening new possibilities, among others, to immunological, biochemical and molecular research.

\section{Acknowledgments}

Acknowledgments for the financially supported by the National Council for Research and Development $(\mathrm{CNPq})$ and the Federal University of Ouro Preto (UFOP). We thank the Laboratory of Experimental Nutrition (LABNEX-UFOP) and the Metabolic Biochemistry Laboratory (LBM-UFOP).

\section{References}

1. Holt PG, Thomas WR, Keast D (1973) Smoking and immunity. Lancet 1: 1316.

2. Kalra R, Singh SP, Savage SM, Finch GL, Sopori ML (2000) Effects of cigarette smoke on immune response: chronic exposure to cigarette smoke impairs antigen-mediated signaling in T cells and depletes IP3-sensitive $\mathrm{Ca}(2+)$ stores. J Pharmacol Exp Ther 293: 166-171.

3. Singh SP, Razani-Boroujerdi S, Pena-Philippides JC, Langley RJ, Mishra NC, et al. (2006) Early postnatal exposure to cigarette smoke impairs the antigenspecific T-cell responses in the spleen. Toxicol Lett 167: 231-237.

4. Higgins S (2002) Smoking in pregnancy. Curr Opin Obstet Gynecol 14: 145151.

5. Contal M, Masson G, Boyer C, Cazevielle C, Mares P (2005) Neonatal consequences of maternal smoking during pregnancy. J Gynecol Obstet Biol Reprod (Paris) 1: 3S215-222.

6. Andres RL, Day MC (2000) Perinatal complications associated with maternal tobacco use. Semin Neonatol 5: 231-241.

7. Cnattingius S (2004) The epidemiology of smoking during pregnancy: smoking prevalence, maternal characteristics, and pregnancy outcomes. Nicotine Tob Res 2: S125-S140.
8. Ino T (2010) Maternal smoking during pregnancy and offspring obesity: metaanalysis. Pediatr Int 52: 94-99.

9. Durmuş B, Ay L, Hokken-Koelega AC, Raat H, Hofman A, et al. (2011) Materna smoking during pregnancy and subcutaneous fat mass in early childhood. The Generation R Study. Eur J Epidemiol 26: 295-304.

10. Ananth CV, Smulian JC, Vintzileos AM (1999) Incidence of placental abruption in relation to cigarette smoking and hypertensive disorders during pregnancy: a meta-analysis of observational studies. Obstet Gynecol 93: 622-628.

11. George L, Granath F, Johansson AL, Annerén G, Cnattingius S (2006) Environmental tobacco smoke and risk of spontaneous abortion. Epidemiology 17: $500-505$

12. Mitchell EA, Milerad J (2006) Smoking and the sudden infant death syndrome. Rev Environ Health 21: 81-103.

13. Lim R, Sobey CG (2011) Maternal nicotine exposure and fetal programming of vascular oxidative stress in adult offspring. Br J Pharmacol 164: 1397-1399.

14. Draper HH, Hadley M (1990) Malondialdehyde determination as index of lipid peroxidation. Methods Enzymol 186: 421-431.

15. van der Vaart H, Postma DS, Timens W, ten Hacken NH (2004) Acute effects of cigarette smoke on inflammation and oxidative stress: a review. Thorax 59: 713-721.

16. Chow CK (1993) Cigarette smoking and oxidative damage in the lung. Ann N Y Acad Sci 686: 289-298.

17. Auharek SA, de Franca LR, McKinnell C, Jobling MS, Scott HM, et al. (2010) Prenatal plus postnatal exposure to Di(n-Butyl) phthalate and/or flutamide markedly reduces final sertoli cell number in the rat. Endocrinology 151: 28682875.

18. Valenca SS, Castro P, Pimenta WA, Lanzetti M, Silva SV, et al. (2006) Light cigarette smoke-induced emphysema and NFkappaB activation in mouse lung Int J Exp Pathol 87: 373-381.

19. Bezerra FS, Valença SS, Pires KM, Lanzetti M, Pimenta WA et al. (2011) Longterm exposure to cigarette smoke impairs lung function and increases HMGB-1 expression in mice. Respir Physiol Neurobiol 177: 120-126.

20. Rodrigues de Araujo G, Granato de Faria K, Lima WG, Pádua BD, Rosson JV, et al. (2011) Effect of captopril and the bradykinin-PKC pathway on ROS production in type 1 diabetic rats. Can J Physiol Pharmacol .

21. Simpson WJ (1957) A preliminary report on cigarette smoking and the incidence of prematurity. Am J Obstet Gynecol 73: 807-815.

22. Chen H, Iglesias MA, Caruso V, Morris MJ (2011) Maternal cigarette smoke exposure contributes to glucose intolerance and decreased brain insulin action in mice offspring independent of maternal diet. PLoS One 6: e27260.

23. Pollard I (1984) Effects of stress administered during pregnancy on reproductive capacity and subsequent development of the offspring of rats: prolonged effects on the litters of a second pregnancy. J Endocrinol 100: 301-306.

24. Ernst M, Moolchan ET, Robinson ML (2001) Behavioral and neural consequences of prenatal exposure to nicotine. J Am Acad Child Adolesc Psychiatry 40: 630-641.

25. Lehtovirta P, Forss M (1978) The acute effect of smoking on intervillous blood flow of the placenta. Br J Obstet Gynaecol 85: 729-731.

26. Jagadapillai R, Chen J, Canales L, Birtles T, Pisano MM , et al. (2012) Developmental cigarette smoke exposure: Kidney proteome profile alterations in low birth weight pups. Toxicology 299: 80-89.

27. Hales CN, Barker DJ (2001) The thrifty phenotype hypothesis. Br Med Bul 60: 5-20.

28. Esposito ER, Horn KH, Greene RM, Pisano MM (2008) An animal model of cigarette smoke-induced in utero growth retardation. Toxicology 246: 193-202.

29. Herscowitz HB, Cooper RB (1979) Effect of cigarette smoke exposure on maturation of the antibody response in spleens of newborn mice. Pediatr Res 13: $987-991$.

30. Chen H, Simar D, Morris MJ (2009) Hypothalamic neuroendocrine circuitry is programmed by maternal obesity: interaction with postnatal nutritional environment. PLoS One 4: e6259.

31. Pirkola J, Pouta A, Bloigu A, Hartikainen AL, Laitinen J, et al. (2010) Risks of 
Citation: Diniz MF, Dourado VA, Silva ME, Pedrosa ML, Bezerra FS, et al. (2013) Cigarette Smoke Causes Changes in Liver and Spleen of Mice Newborn Exposed During Pregnancy. J Cytol Histol 4: 168. doi:10.4172/2157-7099.1000168

Page 5 of 5

overweight and abdominal obesity at age 16 years associated with prenatal exposures to maternal prepregnancy overweight and gestational diabetes mellitus. Diabetes Care 33: 1115-1121.

32. Obici S, Zhang BB, Karkanias G, Rossetti L (2002) Hypothalamic insulin signaling is required for inhibition of glucose production. Nat Med 8: 13761382
33. Lam TK (2007) Brain Glucose Metabolism Controls Hepatic Glucose and Lipid Production. Cellscience 3: 63-69.

34. D’Agostini F, Balansky R, Steele VE, Ganchev G, Pesce C, et al. (2008) Preneoplastic and neoplastic lesions in the lung, liver and urinary tract of mice exposed to environmental cigarette smoke and UV light since birth. Int J Cancer 123: 2497-2502. 